\title{
Elastase inhibitors of sputum sol phase: variability, relationship to neutrophil elastase inhibition, and effect of corticosteroid treatment
}

\author{
RA STOCKLEY, HM MORRISON, JA KRAMPS, JH DIJKMAN, D BURNETT \\ From the Lung Immunobiochemical Research Laboratory, General Hospital, Birmingham, and the University \\ Department of Pulmonologv. Leiden. The Netherlands
}

\begin{abstract}
The concentrations of three known elastase inhibitors $\left(\alpha_{1}\right.$ proteinase inhibitor, antileucoprotease, and $\alpha_{2}$ macroglobulin) have been determined in the sputum of six patients with $\circ$ obstructive bronchitis over five consecutive days. Antileucoprotease was the major inhibitor measured and potentially could provide more than $80 \%$ of the elastase inhibition, whereas the contribution of $\alpha_{2}$ macroglobulin was less than $0.2 \%$. Comparison with the inhibitory capacity of the secretions active against human neutrophil elastase showed that the inhibitors could account for $\vec{\bullet}$ only about half of the inhibition measured. This suggests the presence of a substantial amount of $\%$ unrecognised inhibitor. Corticosteroid treatment in 10 patients reduced the mean $\alpha_{1}$ proteinase inhibitor concentration ( $\mathrm{p}<0.025)$ from $18.6 \mu \mathrm{g} / \mathrm{ml}$ (SD 22.5) to $9.8(6.6)$. Antileucoprotease, however, increased ( $\mathrm{p}<0.05$ ) from $20.5 \mu \mathrm{g} / \mathrm{ml}(24.3)$ to $39.3(23.4)$. These changes were associated with an increase in elastase inhibition ( $\mathrm{p}<0.025)$ from $180(160) \mu \mathrm{g}$ elastase/ml secretion to $310(130)$, suggesting a beneficial effect of steroid treatment on the antielastases in lung secretions.
\end{abstract}

Although the cause of emphysema remains uncertain, the currently favoured hypothesis is that proteolytic enzymes with elastolytic properties digest lung elastin, leading to structural changes and hence dilatation of air spaces. ${ }^{1}$ Before the enzymes can attack lung elastin, however, they must overcome the local inhibitors. The enzyme that has been implicated in human emphysema is neutrophil elastase. ${ }^{1}$ Hence the balance between this enzyme and elastase inhibitors may play a crucial part in the development of emphysema.

There has been controversy about the nature of antielastases in lung secretion. Gadek et $a^{2}$ initially presented data suggesting that the only antielastase of the alveolar structure was $\alpha_{1}$ antitrypsin (also called $\alpha_{1}$ proteinase inhibitor). Although several low molecular weight inhibitors of elastase have been identified in lung secretions, ${ }^{1}$ it was thought that these were inhibitors protecting bronchial rather than alveolar structures. $^{3}$

Recent immunohistochemical evidence, however, has shown that these inhibitors are present in periph-

Address for reprint requests: Dr RA Stockley, General Hospital, Birmingham B4 6NH.

Accepted 6 December 1985 eral airways. ${ }^{4}$ Furthermore, they can be recovered by bronchoalveolar lavage ${ }^{5}$ and contribute substantially to the elastase inhibition in lavage samples. ${ }^{56}$ In addition, we have shown that the relative concentrations of the low molecular weight inhibitors and $\alpha_{1} \underset{\times}{\mathscr{\chi}}$ proteinase inhibitor, as well as their function, are broadly similar in bronchial secretions (sputum) and bronchoalveolar lavage fluid. ${ }^{5}$

The purpose of the present study was to assess the known antielastases in sputum sol phase from 을 patients with chronic bronchitis and emphysema. In particular, we were interested in their contribution to the antielastase activity of the secretion and whether $N$ or not this varied from day to day in a group of subjects. Furthermore, we have obtained preliminary evi- $N$ dence that corticosteroid treatment increases the $\mathrm{\omega}$ elastase inhibition of lung secretions. ${ }^{7}$ Alpha 1 proteinase inhibitor concentrations, however, are lower 0 during steroid treatment, ${ }^{8}$ and we wished to determine whether the increase in elastase inhibition could $\stackrel{?}{+}$ be explained by changes in the other known inhibitors.

\section{Methods}

The study was divided into two parts. Firstly, we studied six patients with smoke related chronic 
obstructive bronchitis (mean FEV 1.23 (SD 0.39) aged 54-67 years. All were current smokers and collected their sputum (as free from saliva as possible) during the first four hours from rising on five consecutive days. Secondly, we studied 10 similar patients (four of them female) aged 45-64 years (mean FEV $0.981(0.27)$ ) while they were in hospital for a trial of steroid treatment. Sputum was collected during their first week of placebo treatment and after five days of steroid treatment ( $40 \mathrm{mg}$ prednisone a day). This time interval had previously been shown to be sufficient to show changes in secretion proteins. ${ }^{8}$ All other treatment remained unaltered.

The sputum was ultracentrifuged to obtain the sputum sol phase, which was divided into two aliquots and stored at $-70^{\circ} \mathrm{C}$ until it was analysed.

\section{PROTEIN CONCENTRATIONS}

The sputum albumin and $\alpha_{1}$ proteinase inhibitor were measured by rocket immunoelectrophoresis with well characterised antiserum known to give accurate results, even for $\alpha_{1}$ proteinase inhibitor that had recently interacted with enzyme. ${ }^{9}$ An aliquot of the samples was flown in dry ice to Leiden for measurement of the low molecular weight bronchial inhibitor antileucoprotease by enzyme linked immunosorbent assay (ELISA ${ }^{10}$ ).

Alpha $_{2}$ macroglobulin was measured by ELISA in our laboratory with a known standard serum and antiserum obtained from the Immunodiagnostic Research Laboratory (University of Birmingham). The lower limit of detection was $2 \mathrm{ng} / \mathrm{ml}$ and the between batch coefficient of variation at $1800 \mathrm{ng} / \mathrm{ml}$ ( $\mathrm{n}=5$ ) was $2.4 \%$.

Comparison of molar amounts of the elastase inhibitors was taken from their concentrations and molecular weights. The values used were 54000 daltons for $\alpha_{1}$ proteinase inhibitor ${ }^{11} ; 14500$ for antileucoprotease $^{10}$ and 725000 for $\alpha_{2}$ macroglobulin. ${ }^{12}$

\section{ENZYME INHIBITION}

The ability of each secretion to inhibit neutrophil elastase was determined by adding increasing volumes of the sample to a known amount of enzyme, ${ }^{5}$ and the inhibitory capacity (volume capable of totally inhibiting the enzyme) was determined by interpolation of the inhibition curve. The amount of enzyme inhibited per $\mathrm{ml}$ of secretion was thus obtained (the neutrophil elastase inhibitory capacity).

On the assumption that the molecular weight of neutrophil elastase is 30000 daltons ${ }^{13}$ we could determine the number of moles in neutrophil elastase inhibited by a given volume of secretion. This result was compared with the number of moles of inhibitor present, as described above. Thus we could determine whether the inhibitors present could account for the inhibition measured. For these calculations we took into account the known observations that $\alpha_{1}$ proteinase inhibitor and antileucoprotease inhibit neutrophil elastase in a 1:1 molar ratio and $\alpha_{2}$ macroglobulin in a 2:1 molar ratio.

Comparisons between results were tested statistically using the Wilcoxon test for paired data (single tailed).

\section{Results}

All samples contained measurable quantities of the three inhibitors. The range between individuals, however, was wide for each of the days, as indicated by the SD values shown in table 1 . The coefficients of variation between subjects $(\mathrm{SD} /$ mean $\times 100)$ for antileucoprotease on the five days were $55 \%, 48.3 \%$, $33.8 \%, 54.9 \%$, and $51.3 \%$. The variability for $\alpha_{1}$ proteinase inhibitor showed a wider range-from $109.8 \%$ (day 1) to $30.5 \%$ (day 3)-and that for $\alpha_{2}$ macroglobulin ranged from $80.8 \%$ (day 1) to $57.9 \%$ (day 3).

Antileucoprotease was the major inhibitor in terms of moles/100 moles of total measured inhibitor. This inhibitor accounted for more than $60 \%$ of the measured inhibitors in all secretions. Alpha ${ }_{1}$ proteinase inhibitor was the second major inhibitor, representing about $10-20 \%$ of the inhibitors measured. The contribution of $\alpha_{2}$ macroglobulin was usually less than

Table 1 Mean (SD) concentrations and percentage molar concentrations (molar ratios) of known protease inhibitors, neutrophil elastase inhibitory capacity, and calculated percentage of unknown inhibitor in sputum from six patients on five consecutive days

\begin{tabular}{|c|c|c|c|c|c|c|c|c|}
\hline \multirow[t]{2}{*}{ Day } & \multicolumn{3}{|c|}{ Concentration $(\mu \mathrm{g} / \mathrm{ml})$} & \multicolumn{3}{|c|}{ Molar ratio (\%) } & \multirow{2}{*}{$\begin{array}{l}N E I C \\
(\mu g / m l)\end{array}$} & \multirow{2}{*}{$\begin{array}{l}\text { Unknown } \\
\text { inhibitor (\%) }\end{array}$} \\
\hline & $A L P$ & $\alpha_{1} P I$ & $\alpha_{2} M$ & $\overline{A L P}$ & $\alpha_{1} P I$ & $\alpha_{2} M$ & & \\
\hline $\begin{array}{l}1 \\
2 \\
3 \\
4 \\
5\end{array}$ & $\begin{array}{l}37(20.5) \\
46.2(22.3) \\
48.3(16.3) \\
42.8(23.5) \\
34.7(17.8)\end{array}$ & $\begin{array}{l}23.5(25.8) \\
21.3(11.4) \\
16.4(5.0) \\
19.7(9.1) \\
16.9(9.9)\end{array}$ & $\begin{array}{l}1.98(1.6) \\
1.47(0.94) \\
0.88(0.51) \\
1.16(0.88) \\
0.97(0.77)\end{array}$ & $\begin{array}{l}84.7(12.3) \\
87.8(5.3) \\
90.6(5.3) \\
87.2(5.8) \\
82.4(11.1)\end{array}$ & $\begin{array}{c}15.2(12.2) \\
12.1(5.3) \\
9.4(5.2) \\
12.7(5.8) \\
17.5(11.0)\end{array}$ & $\begin{array}{l}0.11(0.08) \\
0.08(0.08) \\
0.04(0.04) \\
0.08(0.08) \\
0.08(0.14)\end{array}$ & $\begin{array}{l}167.9(87.8) \\
193.9(80.7) \\
216.4(55.9) \\
207.6(66.9) \\
182.2(57.0)\end{array}$ & $\begin{array}{l}50.0(16.0) \\
51.0(18.0) \\
51.5(12.5) \\
59.2(26.5) \\
68.5(36.7)\end{array}$ \\
\hline
\end{tabular}

ALP—antileucoprotease; $\alpha_{1} \mathrm{PI}-\alpha_{1}$ proteinase inhibitor; $\alpha_{2} \mathrm{M}-\alpha_{2}$ macroglobulin; NEIC - neutrophil elastase inhibitory capacity. 


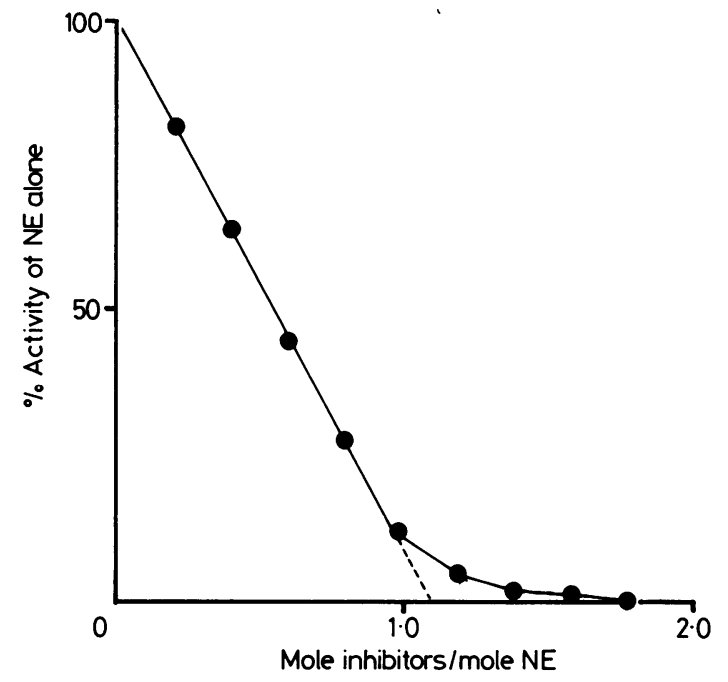

Fig 1 Inhibition of neutrophil elastase (NE) by a mixture of antileucoprotease, $\alpha_{1}$ proteinase inhibitor, and $\alpha_{2}$ macroglobulin. The vertical axis indicates the remaining enzyme activity and the horizontal axis the total moles of inhibitor added per mole of enzyme. The regression line passes through 1:08 moles per mole neutrophil elastase.

$1 \%$ in all the samples and was on average under $0.11 \%$. These results are also summarised in table 1 .

The average between subject results for each protein were similar though not identical on each of the five days. There were no significant differences for any of the results between any two days.

\section{INHIBITION STUDIES}

Before we undertook inhibition studies on samples of sputum the validity of the technique was assessed with a mixture of all three proteins in quantities similar to the average results obtained for the six patients. The inhibition of neutrophil elastase by this mixture is shown in figure 1. Extrapolation of the inhibition line shows that the $x$ intercept occurs close to the point of molar equivalence of enzyme and the total amount of inhibitor.

The results of inhibition studies using samples of sputum are shown in table 1 . The average amount of neutrophil elastase inhibited per $\mathrm{ml}$ of secretion was relatively constant on each of the days, although the range was again wide. The between subject variability ranged from $52.3 \%$ (day 1 ) to $25.8 \%$ (day 3 ).

Despite the variability the amount of enzyme inhibited clearly was more than twice as great on average as the total capacity of the inhibitors measured. Thus more than half of the inhibition could not be accounted for by the total amount of antileucoprotease, $\alpha_{1}$ proteinase inhibitor, or $\alpha_{2}$ macroglobulin. This proportion was relatively constant
$\%$ Elastase

inhibition
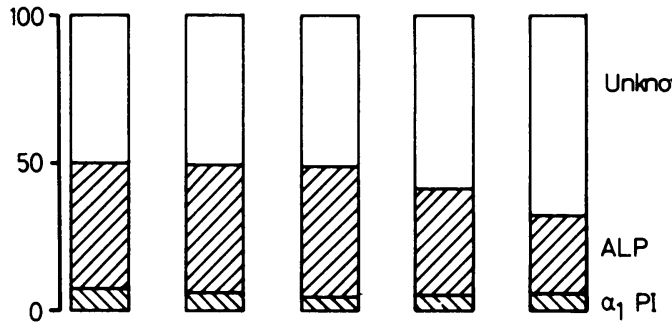

Fig 2 Average potential contribution of antileucoprotease $(A L P)$ and $\alpha_{1}$ proteinase inhibitor $\left(\alpha_{1} P I\right)$ to total elastase inhibition for the six patients on each of the five days.

(table 1); the between subject variability (cofficient of $\stackrel{\circ}{2}$ variance for the five days was $32 \%, 35.3 \%, 24.3 \%$, $44.8 \%$, and $53.6 \%$.

Figure 2 summarises the relative contributions of antileucoprotease and $\alpha_{1}$ proteinase inhibitor to total $\vec{\bullet}$ inhibition and to the proportion unaccounted for. The potential contribution of $\alpha_{2}$ macroglobulin was too small to be illustrated graphically.

\section{EFFECT OF STEROIDS}

Because of the large between subject variability, $10 \stackrel{\circ}{\frac{}{D}}$ subjects were included in the study of the effect of steroid treatment. Measurements of $\alpha_{2}$ macroglobulin $\overrightarrow{\vec{\overrightarrow{ }}}$ were not made because of its minimal contribution to elastase inhibition. The results are summarised in table 2. There was a significant increase $(p<0.05)$ in antileucoprotease concentration during steroid and $\mathrm{a} \overrightarrow{\mathrm{\sigma}}$ significant decrease $(\mathrm{p}<0.025)$ in $\alpha_{1}$ proteinase inhibitor concentration. The neutrophil elastase ${ }_{-}^{x}$ inhibitory capacity rose with steroid treatment 3 . $(p<0.025)$, although the proportion of inhibition that could not be accounted for by antileucoprotease and $\alpha_{1}$ proteinase inhibitor together remained unaltered.

\section{Discussion}

The results of this study show that wide inter- 0 individual variability exists for both the quantity and 0

Table 2 Concentration of protease inhibitors, neutrophil elastase inhibitory capacity, and calculated percentage of unknown inhibitor in 10 patients before and during treatment 0 with corticosteroids

\begin{tabular}{|c|c|c|c|c|}
\hline & \multicolumn{3}{|c|}{ Concentration $(\mu \mathrm{g} / \mathrm{ml})$} & \multirow{2}{*}{$\begin{array}{l}\text { Unknown } \\
\text { inhibitor } \\
(\%)\end{array}$} \\
\hline & $A L P$ & $\alpha_{1} P I$ & $N E I C$ & \\
\hline \multirow{2}{*}{$\begin{array}{l}\text { Control } \\
\text { Steroid } \\
\text { Significance } \\
\text { (p) }\end{array}$} & $\begin{array}{l}20.5(24.3) \\
39.3(23.4)\end{array}$ & $\begin{array}{c}18.6(22.5) \\
9.8(6.6)\end{array}$ & $\begin{array}{l}180(160) \\
310(130)\end{array}$ & $\begin{array}{l}64.9(30.3) \\
69.2(19.5)\end{array}$ \\
\hline & $<0.05$ & $<0.025$ & $<0.025$ & NS \\
\hline
\end{tabular}

Abbreviations as in table 1 . 
the function of proteinase inhibitors in sputum. The variability is similar to that found previously for other proteins in sputum from similar patients. ${ }^{14}$ The reasons for such variability have been discussed in detail $^{15}$ and reflect the problems of sample collection, local production, and lung inflammation that may vary even in an apparently homogenous group of patients. This emphasises the importance of the requirement that clinical studies in which minor biochemical changes are expected must include sufficient subjects for them to be detected.

The results show that antileucoprotease is the major elastase inhibitor of those measured in bronchial secretions, accounting on average for over $80 \%$ of the total molar amount of known inhibitors. On the basis of the results presented here $\alpha_{2}$ macroglobulin is unlikely to have a significant antielastase role in these secretions. The low levels found confirm our previous findings ${ }^{16}$ and reflect the restriction of $\alpha_{2}$ macroglobulin diffusion from serum because of its large molecular size.

Of greater interest are the results of neutrophil elastase inhibition. Again, we found wide variability between subjects (table 1). Furthermore, the degree of enzyme inactivation could not be explained by the measured inhibitors. On average about half of the enzyme inhibition appeared to be due to an unknown inhibitor or inhibitors. Although this supports the recent work of Tournier and colleagues, ${ }^{17}$ its validity clearly depends on the accuracy of the methods. If the inhibitors are underestimated or the inhibition is overestimated by a sufficient degree, the discrepancy observed will clearly reflect technical problems alone.

The measurement of lung inhibitors, particularly $\alpha_{1}$ proteinase inhibitor, may present problems when the protein in the secretion is physicochemically different from the protein standards. ${ }^{15}$ The assay for $\alpha_{2}$ macroglobulin is clearly reproducible and because of its low concentration even major inaccuracies in its measurement would be unlikely to effect the overall results. The $\alpha_{1}$ proteinase inhibitor assay is also reproducible, but $\alpha_{1}$ proteinase inhibitor can be overestimated in immune assays if a major proportion has undergone proteolytic cleavage. ${ }^{9}$ Proteolytic cleavage, however, also inactivates $\alpha_{1}$ proteinase inhibitor as an inhibitor. Thus if such a change had occurred it would lead to overestimation of its possible contribution to elastase inhibition as studied here.

The assay for antileucoprotease is the least precise, although even the $13 \%$ between batch coefficient of variation would not be sufficient to produce a major underestimation of its concentration. Such a change would have to occur regularly to explain the discrepancy between measured inhibitors and the inhibitory capacity. Inaccuracies in the estimation of inhibitor are therefore unlikely to account for the results, which have led to the suggestion that unknown inhibitors exist.

Several errors may arise in assessing enzyme inhibition with low molecular weight substrate such as that used here. ${ }^{15}$ In particular, it is vital that the activity of the enzyme is determined by active site titration as a degree of inactivation occurs with purification. Failure to take this into account will result in an overestimation of enzyme inhibition. This is not the case in the studies reported here since it is our routine practice to report results in terms of active enzyme only.

$\mathrm{Alpha}_{2}$ macroglobulin does not inactivate neutrophil elastase when small peptide substrates are used. ${ }^{18}$ This could lead to an apparent discrepancy between the expected and observed inhibition of neutrophil elastase when the current methods are used. The contribution of $\alpha_{2}$ macroglobulin is potentially very small, however, and would if anything lead to an overestimation of its contribution to the neutrophil elastase inhibition seen here.

On balance the results seem to indicate that elastase inhibitors other than those measured are present in considerable quantities in these samples. As a further confirmation, we prepared mixtures of active antileucoprotease, $\alpha_{1}$ proteinase inhibitor, and $\alpha_{2}$ macroglobulin in ratios similar to those in our bronchitic sputum. The inhibition of neutrophil elastase determined by the same assay is shown in figure 1 and confirms that the regression line passes close to molar equivalence (see under "Results").

The nature of the unidentified inhibitor or inhibitors is uncertain. Several low molecular weight inhibitors of elastase have been purified by different research groups. ${ }^{1}$ The relationship between these inhibitors is not clear and may partly represent methodological problems of purification. Indeed, Keuppers and Bromke ${ }^{19}$ were able to purify several different molecular weight inhibitors with immunological similarity from the same samples. It is thus possible that all of the inhibitors isolated by different groups may be fragments of the same protein. If this is the case, the purification that takes place before an antiserum is developed may result in immunological assays that do not quantify all forms of the parent protein equally. The net result could be an underestimation of antileucoprotease or its precursors and hence an underestimation of its contribution to the observed enzyme inhibition, and this could explain our results. Clearly further studies are required to clarify these possibilities. Indeed, whether or not antileucoprotease, as measured here, and the bronchial mucus proteinase inhibitor measured in a previous collaborative study ${ }^{5}$ are the same protein can be determined only by careful comparison of samples from each research group.

In addition, recent studies have identified an 
inhibitor that is functionally distinct from the mucus inhibitors. ${ }^{20}$ This protein can inhibit both neutrophil and porcine pancreatic elastase but not trypsin or cathepsin G. ${ }^{20}$ This inhibitor is, however, present only in low concentrations in sputum, providing about $10 \%$ of the potential inhibition produced by antileucoprotease. ${ }^{20}$ This inhibitor alone is therefore unlikely to account for the discrepancy between inhibition and measured inhibitors observed here.

Corticosteroid treatment was shown to have three major effects. Firstly, the concentration of $\alpha_{1}$ proteinase inhibitor in the secretions fell. This is consistent with a decrease in diffusion of this protein from serum into the secretions as a result of the antiinflammatory effect of the drug. Secondly, there was a rise in the concentration of the locally produced protein antileucoprotease. The reasons are at present uncertain. It is, however, in keeping with the previously noticed rise in another "locally produced" proteinase inhibitor, $\alpha_{1}$ antichymotrypsin. ${ }^{8}$ The result could be due to increased production of antileucoprotease in the lung or a reduction in secretion volume due to the anti-inflammatory properties of corticosteroids. Further studies will be required to determine the exact mechanism. Thirdly, the neutrophil elastase inhibitory capacity rose during steroid treatment. This was not just the result of an increase in antileucoprotease concentration since the proportion of inhibition not accounted for by antileucoprotease and $\alpha_{1}$ proteinase inhibitor remained unaltered. Whatever the mechanisms, the results suggest a beneficial change with an overall increase in the elastase inhibitory capacity of secretions.

Similar effects have also been seen on other enzyme-inhibitor systems in lung secretions. Corticosteroid treatment reduces cysteine proteinase activity $^{21}$ and leads to greater concentrations of a metalloproteinase inhibitor and collagenase inhibition in sputum. ${ }^{22}$ Further studies of the true effect of corticosteroids on proteinase release and inhibitor function in lung secretions may provide valuable information on their role in protection and damage of lung tissues.

Long term corticosteroid treatment is unlikely to become a routine measure for the prevention of emphysema. Nevertheless, the results presented here suggest that therapeutic intervention can modify the antielastases in lung secretions and this is worthy of further study.

We would like to acknowledge the financial support of the General Hospital Bicentenary Fund, the EE Lawley Foundation, and the West Midlands Regional Health Authority. We thank Miss K Roberts for typing the manuscript.

\section{References}

1 Stockley RA. Proteolytic enzymes, their inhibitors and lung disease. Clin Sci 1983;64:119-26.

2 Gadek JE, Fells GA, Zimmerman RL, Rennard S, Crystal RG. Anti-elastases of the human alveolar structures: assessment of the protease-antiprotease theory of emphysema. J Clin Invest 1981;68:889-98.

3 Gadek JE, Fells GA, Zimmerman RL, Crystal RG. Role of connective tissue proteases in the pathogenesis of chronic inflammatory lung disease. Environ Health Persp 1984;55:297-306.

4 Mooren HWD, Kramps JA, Franken C, Meyer CJLM, Dijkman JA. Localisation of a low-molecular-weight bronchial protease inhibitor in the peripheral human lung. Thorax 1983;38:180-3.

5 Stockley RA, Morrison HM, Smith S, Tetley T. Low molecular mass bronchial proteinase inhibitor and $\alpha_{1}$ proteinase inhibitor in sputum and bronchoalveolar lavage. Hoppe-Seylers Z Physiol Chem 1984;365:587-95.

6 Boudier C, Pelletier A, Pauli G, Bieth JG. The functional activity of $\alpha_{1}$ proteinase inhibitor in bronchoalveolar lavage fluids from healthy human smokers and nonsmokers. Clin Chim Acta 1983;132:309-15.

7 Morrison HM, Stockley RA. Antielastase activity of lung secretions and the effect of corticosteroids [abstract]. Am Rev Respir Dis 1984;129, No 4 part 2:A301.

8 Wiggins J, Elliott JA, Stevenson RD, Stockley RA. Effect of corticosteroids on sputum sol-phase protease inhibitors in chronic obstructive pulmonary disease. Thorax 1982;37:652-6.

9 Stockley RA, Afford SC. The immunological assessment of $\alpha_{1}$ antitrypsin with reference to its function in bronchial secretions. Clin Sci 1983;65:373-81.

10 Kramps JA, Franken C, Dijkman JH. ELISA for quantitative measurement of low-molecular-weight bronchial protease inhibitor in human sputum. Am Rev Respir Dis 1984;129:959-63.

11 Baumstark JS, Ting Lee C, Luby RJ. Rapid inactivation of $\alpha_{1}$ proteinase inhibitor ( $\alpha_{1}$ antitrypsin) by elastase. Biochim Biophys Acta 1977;482:400-11.

12 Fryksmark U, Ohlsson K, Rosengren M, Tegner H. Studies on the interaction between leukocyte elastase, antileukoprotease and the plasma proteinase inhibitors, $\alpha_{1}$ proteinase inhibitor and $\alpha_{2}$ macroglobulin. Hoppe Seylers Z Physiol Chem 1983;364:793-800.

13 Jochum M, Lander S, Heimburger N, Fritz H. Effect of human granulocytic elastase on isolated human anti- $\frac{}{2}$ thrombin III. Hoppe Seylers Z Physiol Chem 1981;362:103-12.

14 Wiggins J, Stockley RA. Variability in sputum sol-phase proteins in chronic obstructive bronchitis. The value of using albumin for standardisation. Am Rev Respir Dis 1983;128:60-4.

15 Stockley RA. Measurement of soluble proteins in lung secretions. Thorax 1984;39:241-7.

16 Burnett D, Stockley RA. Serum and sputum $\alpha_{2}$ macroglobulin in patients with chronic obstructive airways disease. Thorax 1981;36:512-6.

17 Tournier JM, Jacquot J, Puchelle E, Bieth JG. Quantitation of bronchial inhibitor in bronchial liquids by radial immunodiffusion and ELISA methods [abstract]. Am Rev Respir Dis 1985;131:A370.

18 Barrett AJ, Brown MA, Sayers CA. The electro- O् phoretically "slow" and "fast" forms of $\alpha_{2}$ macroglobulin molecule. Biochem J 1979;181:401-18. 
19 Keuppers F, Bromke BJ. Protease inhibitors in tracheobronchial secretions. J Lab Clin Med 1983;101:747-57.

20 Kramps JA, Klasen EC. Characterisation of a low molecular weight anti-elastase isolated from human bronchial secretion. Exp Lung Res (in press).

21 Burnett D, Stockley RA. Cathepsin B-like cysteine proteinases activity in sputum and bronchoalveolar lavage samples: relationship to inflammatory cells and effects of corticosteroids and antibiotic treatment. Clin Sci 1985;68:469-74.

22 Burnett D, Reynolds J, Afford SC, Stockley RA. Tissue inhibitor of metallo proteinases and collagenase inhibition in lung secretions [abstract]. Clin Sci 1985;69, suppl 12:78-9P. 